\title{
Groundwater management issues in Southern Africa - An IWRM perspective ${ }^{\#}$
}

\author{
Eberhard Braune* and Yongxin Xu \\ Department of Earth Sciences, University of the Western Cape, South Africa
}

\begin{abstract}
In contrast to its strategic role as essential resource to help achieve community development and poverty alleviation in the Southern African Development Community (SADC), groundwater has remained a poorly understood and managed resource. This was the finding of a scoping study regarding the status of groundwater resources management in SADC. The key premise for the assessment was that groundwater resource management must take place within an IWRM framework and the IWRM Toolbox developed by the Global Water Partnership was used as the scope and content for the assessment. The SADC region has well- developed policies for regional development and IWRM, as well as a relatively strong focus on groundwater resources. This article questions whether problems relating to Africa's sustainable utilisation and management of groundwater is a unique groundwater problem or must also be related to the challenges experienced in general with the implementation of an IWRM approach in Africa. A key finding was that groundwater management links to groundwater-dependent sectors like agriculture, rural development, health and environment are not well- established in policy or in practice. Internationally, there is a recognition, that such a, quite common, situation can only be addressed through a long-term process through which viable national, regional and local systems can evolve, within a strategic framework in which these intended relationships between diverse sets of interventions or management approaches and the development goals are brought out. However, such a strategic, multi-stakeholder-driven approach also still remains the major challenge in Africa for IWRM implementation as a whole. Recent continent-wide initiatives, like the development of IWRM and water efficiency plans for each country and multi-stakeholder water dialogue processes, have been taken to address this challenge. It is therefore crucial that groundwater becomes an integral part of these and related initiatives. New AMCOW and SADC initiatives for groundwater provide a major opportunity to achieve this.
\end{abstract}

Keywords: groundwater, community development, sustainable utilisation and management, IWRM

\section{Introduction}

The Africa Regional Document to the $4^{\text {th }}$ World Water Forum provides a good summary of the water and development situation (World Water Council, 2006). Water is a key factor in Africa's development. Nonetheless, the African continent has to date used only a small proportion (5\%) of its available water resources. The African water crisis, often referred to in international forums, is therefore a lot more complex than continental water availability. Key is the large spatial and temporal variability of resource availability, going with the more arid climate prevalent in about $60 \%$ of the African continent and the widespread lack of skilled and experienced human resources to manage the irregular availability of water, e.g. through building balancing storage, transferring water between water-rich and water-poor areas and implementing water conservation and demand management.

There is now a growing perception that local groundwater resources will have to play an increasingly strategic role in Africa, in particular for the most vulnerable and most neglected

\# Revised version. Originally presented at the International Conference on Integrated Water Resource Management (IWRM) entitled: Lessons from Implementation in Developing Countries which took place from 10 to 12 March 2008 in Cape Town, South Africa, at the Cape Town International Convention Centre.

* To whom all correspondence should be addressed.

学 +2782 310 8183; fax: +2712 8033 527; e-mail: bbraune@uwc.ac.za rural communities (AMCOW, 2008; ECA et al., 2000). Crucial in this regard is that, in sub-Saharan Africa, $300 \mathrm{~m}$. people still have no access to safe water supplies - approximately $80 \%$ of these live in rural areas (World Water Council, 2006). The health and socio-economic implications of this situation are enormous in terms of morbidity, mortality and sickness from water and sanitation related diseases. Therefore, significantly increasing the coverage of rural water supply in Africa is fundamental to achieving the Millennium Development Goals (MDGs) The challenge lies not so much in stretching local groundwater resources, but in integrated local development efforts.

In contrast to this strategic role for groundwater, it has remained a poorly understood and managed resource (BGR et al., 2007; FAO, 2003). Pollution of the vital underlying groundwater sources in African cities as well as in many rural communities has reached critical levels (Xu and Usher, 2006). This has become a clear threat to water service delivery and meeting the MDGs on water. The overarching challenge has therefore become the sustainable utilisation of local groundwater resources.

Most African countries have adopted IWRM as their principal approach to water resource management (World Water Council, 2006). This article questions whether problems relating to Africa's sustainable utilisation and management of groundwater resources are unique groundwater problems or should also be related to the challenges experienced in general with the implementation of an IWRM approach in Africa. Findings of a scoping study regarding the state of groundwater resource management in the Southern African Development Community are 
interpreted in relation to IWRM 'best practice'. A broad way forward is discussed in relation to recent groundwater-related resolutions adopted by the African Ministers Council on Water (AMCOW).

\section{IWRM challenges in Africa}

The concern and challenge that was posed by Agenda 21 for fresh water resources, and which introduced IWRM thinking worldwide, clearly also holds for groundwater:

'Scarcity and misuse of fresh water pose a threat to development and protection of the environment. Human health and welfare, food security, industrial development, and ecosystems on which they depend are all at risk unless water and land are managed more effectively than they have been in the past’' (United Nations, 1992)

The challenges of sustainable development led to increasing 'integration' requirements, which are well captured in the IWRM definition from the Global Water Partnership:

'IWRM is a process which promotes the coordinated development and management of water, land and related resources in order to maximise the resultant economic and social welfare in an equitable manner without compromising the sustainability of vital ecosystems.'

Integrated management approaches are required that are designed to change the way people view and use the resource. According to Burke and Moench (2000), this involves an appreciation of three effective levels of integration, i.e. integration within the hydrological cycle (the physical processes), integration across river basins and aquifers (spatial integration), and integration across the overall social and economic fabric at national and regional level. Areas requiring more coordinated development and management have also been summarised by the Global Water Partnership (2000) and can all be seen from a groundwater perspective:

- Freshwater and coastal zone management

- Land and water management

- Surface and groundwater management

- Quantity and quality in water resources management

- Upstream and downstream water-related interests

- Mainstreaming of water resources in socio-economic activities

- Cross-sectoral integration in national policy development

- Macro-economic effects of water development.

In pursuing IWRM comprehensively, there is a need to recognise some overriding criteria that take account of social, economic and natural conditions (Global Water Partnership, 2000):

- Economic efficiency in water use: Because of the increasing scarcity of water and financial resources, the finite and vulnerable nature of water as a resource, and the increasing demands upon it, water must be used with maximum possible efficiency

- Equity: The basic right for all people to have access to water of adequate quantity and quality for the sustenance of human wellbeing must be universally recognised

- Environmental and ecological sustainability: The present use of the resource should be managed in a way that does not undermine the life-support system thereby compromising use by future generations of the same resource.
Implementing an IWRM process is a question of getting the 'three pillars' right: moving toward an enabling environment of appropriate policies, strategies and legislation for sustainable water resource development and management; putting in place the institutional framework through which the policies, strategies and legislation can be implemented; and setting up the management instruments required by these institutions to do their job (Global Water Partnership, 2000).

In practice, however, integration still focuses largely on the water-supply-and-use-system itself - not the economic and social factors determining water demand or the distribution of pollution (Burke and Moench, 2000). This is particularly the case in river basin management.

The challenges of comprehensive integration can be illustrated through the gradual process towards IWRM in Africa. The African Ministers Council on Water (AMCOW) and many African countries have adopted IWRM as their vision and approach for water resource management (SADC, 2005; World Water Council, 2006). The particular water management challenges that IWRM must address here can best be illustrated by the Africa Water Vision (Economic Commission for Africa et al., 2000):

'An Africa where there is an equitable and sustainable use and management of water resources for poverty alleviation, socio-economic development, regional cooperation, and the environment.'

As part of this vision, Africa has embraced the MDGs, the centrepiece of the global development agenda, intended to reduce significantly by 2015 vicious cycles of global poverty, hunger, disease, illiteracy, environmental degradation and gender inequality. While water is key to each of the development goals, the initial water focus has been on Target 10: Halve by 2015 the proportion of people without sustainable access to safe drinking water and sanitation (UN Millennium Project Task Force on Water and Sanitation, 2005). This has introduced a strong shift all over Africa from a water resource management and sustainability focus to service delivery. This shift brought about a decentralisation of service delivery, and often completely new institutions at national level, separate from the traditional water resource management institutions, to regulate and support this process. These changes have been highly significant for groundwater, because its role in Africa is strongly tied to community water supply (BGR et al., 2007).

Only through renewed political pressures for the water sector to address growth and development comprehensively, is there a new opportunity to realistically work towards IWRM in Africa. This can be illustrated by some proposed key responses of the South African water sector to the 'Water for Growth and Development Strategy' (DWAF, 2008):

- Strengthen sector collaboration between water services and water resource management

- Engage with other sectors to ensure good governance

- Enhance integrated participatory planning for multiple use water services as part of integrated development plans of local government

- Place development benefits of water at core of financial strategies and national development plans.

A key mechanism to help achieve this resulted from the decision at the World Summit on Sustainable Development (WSSD) held in Johannesburg in 2002, for countries to 'develop integrated water resource management and water efficiency plans by 2005 , 
with support to developing countries.' (WSSD Plan of Implementation, 2002). Throughout Africa a process is underway to achieve this objective and national plans are beginning to appear (Zambian Water Partnership, 2008).

\section{Groundwater's role in Southern Africa}

Groundwater occurrence in Southern Africa is characterised by the large variety of geological structures and the climatic differences that condition the regional hydrogeological settings. Groundwater characteristics in the region are well summarised in a recent survey regarding capacity for groundwater management in West and Southern Africa (BGR et al., 2007). According to this report approximately 60 to $65 \%$ of the region is covered by crystalline rocks with aquifer systems developed in the weathered regolith and in the fractured bedrock. The aquifers developed in these areas are largely unconfined, locally developed and not spatially extensive. Generally, only modest groundwater supplies can be abstracted sustainably from these aquifers and large-scale groundwater well-field developments are not feasible.

Because of semi-arid and arid conditions, especially in southern Angola, Namibia, Botswana, western South Africa, and western Zimbabwe, all have lower recharge rates and hence tend to place a higher value on their water resources than the humid countries. In these areas, groundwater recharge may be limited and probably largely localised to line and point sources such as streambeds and dam basins, respectively (Xu and Beekman, 2003). Surface water resources are largely ephemeral, and most perennial rivers in these areas receive their recharge from the humid areas. As a result, the groundwater resource has assumed great importance as the principal source of freshwater. In contrast the eastern and northern part of the SADC region may be characterised as humid tropical and humid equatorial climates. These areas generally have more abundant water resources, with perennial surface water. The groundwater resource, while potentially more abundant than in the arid countries, receives less attention and is generally not as carefully monitored and managed.

Drought is essentially endemic in the SADC Region and presents a major challenge to the achievement of sustainable development. Events like the 1991/92 drought had a regional impact, causing substantial socio-economic hardships, decline in public health on a large scale, land degradation and bio-diversity losses. Presently, about one third of the people in the region live in drought-prone areas. These extreme events are impacted by global climate changes, and their frequency and intensity are expected to increase in the future (UNESCO, 1999).

Groundwater is the largest water supply source for the domestic water supplies in the SADC Region, while it also plays a significant role in stock watering and other uses (see Table 1). Its contribution to total utilisation in the Region is estimated at $11.6 \%$ by volume, while in domestic supplies it contributes approximately $20 \%$ by volume (Molapo et al., 2000).

Groundwater contribution is very critical to the majority of the rural community and small towns. In areas where rural infrastructure is minimal, rural communities often rely only on informal, traditionally developed groundwater sources (i.e. hand-dug wells, springs, sand, and river abstraction). It should be noted that there is still a backlog of between 30 and $50 \%$ in terms of access to improved water sources in several countries of the region, the largest un-served portion of un-served being in the rural areas. Groundwater resources should thus be seen as strategic within the SADC (Molapo and Puyoo, 2002).

Groundwater's changing role can best be illustrated with the example of South Africa (Braune et al., 2008). Until the new National Water Act of 1998, groundwater was defined in law as 'private water' and was seen of local importance only. With the democratisation of the country in 1994 there was a strong policy shift towards providing basic services, including water and sanitation services, to the whole population as soon as possible. The indication at that time was that $15 \mathrm{~m}$. people or about $40 \%$ of the population did not have the most basic form of water supply. By 2006 the backlog had been reduced to $4 \mathrm{~m}$. and groundwater has played a major role in this regard. Already the rural domestic use from groundwater in South Africa has increased from $120 \times 10^{6}$ $\mathrm{m}^{3}$ in 1986 to $310 \times 10^{6} \mathrm{~m}^{3} / \mathrm{a}$ in 2000 . Overall, more than $60 \%$ of the country's population is supplied with water through groundwater and this number increases to $90 \%$ in some provinces.

A similar picture of groundwater's growing importance is emerging from other Southern African countries with a high proportion of basement aquifers. In Zimbabwe $70 \%$ of the rural population relies on groundwater (Sunguro et al., 2000) and in Swaziland this figure is as high as $90 \%$ (Integrated Regional Information Networks, 2002). Overall, it is estimated that $75 \%$ of the African population is using groundwater as its main

TABLE 1

Summary of groundwater dependency in the SADC Region

\begin{tabular}{|c|c|c|c|c|c|}
\hline Member State & Rural & Urban & Agriculture & Industry & Overall dependency \\
\hline Angola & $* *$ & $* *$ & $* *$ & $*$ & $* *$ \\
\hline Botswana & $* * *$ & $* *$ & $* * *$ & $* * *$ & $* * *$ \\
\hline D R Congo & $*$ & $*$ & $*$ & * & $*$ \\
\hline Lesotho & $* *$ & $* *$ & * & $*$ & $*$ \\
\hline Malawi & $* * *$ & $*$ & $* *$ & * & ** \\
\hline Mauritius & $* *$ & $* *$ & $* *$ & $* *$ & $* *$ \\
\hline Mozambique & $* *$ & $* *$ & $*$ & $*$ & $* *$ \\
\hline Namibia & $* * *$ & $* * *$ & $* * *$ & $* * *$ & $* * *$ \\
\hline Seychelles & $* *$ & $* *$ & * & * & * \\
\hline South Africa & $* * *$ & $* *$ & $* *$ & $* *$ & $* *$ \\
\hline Swaziland & $* * *$ & $*$ & $* *$ & $*$ & $* *$ \\
\hline Tanzania & $* * *$ & $* *$ & $* *$ & * & $* *$ \\
\hline Zambia & $* *$ & $* *$ & $*$ & $* *$ & $* *$ \\
\hline Zimbabwe & $* * *$ & $* *$ & $* * *$ & $* *$ & $* * *$ \\
\hline
\end{tabular}

Scale *** major, ** moderate, * minor Adjusted from Wellfield Consulting Services \& British Geological Survey, 2003 
source of drinking water (ECA et al., 2000).

Although the importance of groundwater as a viable and economically feasible source is now widely recognised in the Region, its importance for bigger settlements and larger-scale water supply is often underplayed. It is estimated that $36 \%$ of the urban population in the SADC Region relies on groundwater (Molapo et al., 2000).

Groundwater is also a major source for small-scale irrigation and livestock farming in many of the SADC Member States. Groundwater for these purposes is largely developed at private level and, as such, reliable statistics are not available. It is estimated that groundwater now accounts for about $14 \%$ of the total irrigated area in Namibia, $18 \%$ in South Africa, and as much as $56 \%$ in Botswana (FAO AQUASTAT database). Small-scale irrigation using groundwater offers a big opportunity for enhancing the livelihoods of the poor in much of Africa and is set to increase in the near future (Wellfield Consulting Services \& British Geological Survey, 2003; FAO, 2003).

\section{Status of groundwater resource management in the SADC Region}

An assessment of the status of groundwater resource management in Southern Africa was recently undertaken at a scoping (desk study) level. The purpose of the assessment was to position the Region for a possible piloting of the 2007 resolutions of AMCOW (African Ministers' Council on Water) regarding groundwater resource management in Africa (Braune et al., 2008).

The SADC Region was chosen because of its well-developed policies for regional development and IWRM, as well as its relatively strong focus on groundwater resources. The overarching goal of the SADC is 'Regional Integration and Poverty Eradication'. Cooperation in various sectors was initiated by way of protocols to the SADC Treaty, protocols being instruments in international law. In the case of water, there is the SADC Protocol on Shared Watercourses, which was enacted during 1998 and was revised in 2003. The Protocol fully caters for groundwater (SADC, 2000). At a planning level, work on a regional strategy for the newly formed water sector was initiated in 1996 and its first 5-year programme became the RSAP-IWRM (1999-2004). One of the components of the integrated action plan is a Groundwater Programme. A comprehensive Regional Water Policy and a Regional Water Strategy have been developed since then. An important vehicle for implementing this policy is the existence of well-functioning river basin organisations (RBOs), mandated by the Protocol and operating under sound legislation and systems for planning and stakeholder involvement and embracing IWRM principles (SADC, 2005).

The approach adopted in the scoping study was to assess the groundwater resource management status in the SADC based on available groundwater documents and scientific literature from the area and to weigh it up against some form of generally accepted 'best practice', summarised from the international groundwater management literature, to obtain a measure of management status. The key premise for the assessment methodology was that groundwater resource management must take place within an IWRM framework and to achieve this, the IWRM Toolbox developed by the Global Water Partnership (Global Water Partnership, 2002) was used as the scope and content for the assessment under the main headings of 'Enabling Environment', Institutional Development' and 'Management Measures'. A management performance rating of 'good', 'limited' or 'below expectation' was assigned to different elements within this framework, by comparison with the benchmark provided in the best practice analysis.

The assessment took into account the socio-economic development situation and the status of water resource management in SADC to ensure that different aspects of groundwater management were relevant in the area.

SADC is made up of 14 Member States at different stages of development, but predominantly underdeveloped. Poverty is widespread in the sub-region, with an estimated $70 \%$ of the population living below the international poverty line of US\$2/d (roughly ZAR20/d), and 40\% living in extreme poverty (less than US\$1/d) (Economic Commission for Africa, 2006). In spite of the economic imbalances amongst its Member States and the relatively small size of the market (only comparable to Belgium or Norway), in the African context the SADC's aggregate GDP of US\$226 bn. is more than double that of ECOWAS, and equivalent to more than half the aggregate GDP of Sub-Saharan Africa (SSA). It also has the highest GNP per capita in the whole of SSA (Economic Commission for Africa, 2006).

The socio-economic conditions characterising the SADC sub-region include rapid population growth, high rates of urbanisation, high HIV/AIDS and malaria prevalence, high levels of poverty and income inequality, and a high incidence of food insecurity (Economic Commission for Africa, 2006). These socioeconomic drivers have placed an increasing demand for water resulting in increased stress on the limited water resources, and exacerbated competition and conflict between and among sectoral users (Economic Commission for Africa, 2006).

Many and diverse factors are affecting poverty in the region, of which water and its appropriate management is just one, albeit an important one. An integrated development approach is thus critical and this is what the Regional Indicative Strategic Development Plan tries to achieve in the SADC. In recognition of the magnitude of the poverty problem, the ultimate objective of the plan, designed to provide strategic direction to SADC programmes, projects and activities, is to deepen the integration agenda of SADC with a view to accelerating poverty eradication and the attainment of other economic and non-economic development objectives (SADC, 2003).

While the above analysis was only performed on readily available published material from the region and without individual country information, some general conclusions on the status of groundwater resource management in SADC can be drawn (Braune et al., 2008):

- Access to reliable and safe water supplies is one of the highest regional development issues, particularly for the high percentage of poor living in largely un-served rural and also peri-urban areas.

- SADC has made excellent progress to address groundwater in its comprehensive regional water resource policies and strategies and in initiating implementation through its Groundwater Management Programme. In this respect SADC is leading the other regional economic communities.

- With regard to implementation in individual countries, the performance in groundwater resource management must still be generally rated as 'below expectation', compared to relevant international best practice. This is the case across the full spectrum of IWRM frameworks used in the analysis.

- A few countries have legislation specifically focusing on groundwater, while others have modern integrated legislation. However, several countries have outdated legislation and, while harmonisation across the region is on the SADC agenda, this has not yet been implemented for groundwaterrelated legislation. 
- Despite the inability of bulk water supply solutions to address most of the widespread and diffuse water demand required to meet the remaining water services backlogs, there is still a general bias towards surface water resources in the region. Groundwater management links to groundwater-dependent sectors like agriculture, rural development, health and environment are not well established in policy or in practice.

- Investment in groundwater, relative to its potential to address national objectives, is limited and is still offset by pollution and ineffective maintenance, making a large proportion of water points inoperative.

- The relatively low priority accorded to groundwater is reflected in funding commitments, in particular for vital but completely inadequate groundwater monitoring, exploration and data gathering.

- Major changes in institutional development for water service delivery and IWRM are taking place in SADC, but groundwater's unique role has not been adequately reflected in this new development, for example in river basin organisations and water user associations (WUAs)

- While decentralisation is becoming a common feature in SADC, institutions have not yet been properly capacitated in terms of their new groundwater responsibility.

- Lack of adequate monitoring and assessment of groundwater resources is resulting in poor attention to groundwater planning at all levels. This is particularly serious for droughtrisk management in which groundwater resources should play a critical role.

- A lack of macro-planning for groundwater prevails, as most of the programmes are undertaken on an ad hoc or crisis response basis. This is one of the most problematic areas in relation to groundwater development (SADC-WSCU, 2001).

- The dependence of the majority of the SADC Member States on external funding sources has an important bearing on groundwater development in these member states, particularly with respect to the establishment of a stable local development capacity. Donor- (and country-) funded groundwater projects are usually of short duration, with little if any hydrogeological monitoring input in their design.

\section{Challenges and opportunities for groundwater within an IWRM framework}

The above analysis indicates that, in relative terms, the SADC has made considerable progress in bringing important groundwater resources into an IWRM framework. However, this is not yet reflected in the groundwater resource management situation in individual countries, which is still rated 'below expectation'. This is obviously a much more general problem, than in this particular region of the world. Groundwater is often a cornerstone in the foundation of many economic and environmental systems. However, even in the contemporary accounts of 'integrated' water management, the unique nature of the groundwater system that underpins the entire resource base, is rarely discussed and addressed (Burke and Moench, 2000).

Some of the particular challenges to groundwater resource management relate to its unique nature. It is a:

- Hidden, unnoticed and less understood resource

- Generally occurring, widely spread and locally accessible resource.

Because the links between users and the resource are often not apparent, and because many of the benefits associated with groundwater are public goods (such as environmental maintenance, health and poverty alleviation), the overall economic value of groundwater goes unrecognised (Burke and Moench, 2000). This situation has led to lack of attention in general to groundwater by decision-makers and a lack of progress in formally treating it as part of IWRM. At this moment, a potential opportunity for much increased recognition of groundwater's role in Africa may lie in the political pressures, touched on under 'IWRM challenges in Africa', for the water sector to address growth and development comprehensively. This can be illustrated with a few proposed groundwater-related responses of the South African water sector to the 'Water for Growth and Development Strategy’ (DWAF, 2008):

- Focus on multiple uses of water for poverty alleviation and improved livelihoods

- Need groundwater for multiple uses to achieve spatial equity

- Need subsidisation of appropriate technology (for local resource development).

Besides the valuation there is the management issue. Because of its ubiquitous nature and relative ease of local access, there are widely distributed and generally dispersed abstraction points and many stakeholders, who are involved in its development, use, as well as misuse. This complicates the traditional national approaches to resource regulation and requires a very high degree of participative management. It also requires novel approaches to the systematic planning, financing and implementation of hundreds and even thousands of small, locally dispersed groundwater schemes (Braune et al., 2008 and Burke and Moench, 2000).

In probably one of the most insightful groundwater resource management books entitled: 'Groundwater and Society Resources, Tensions and Opportunities', Burke and Moench (2000) make a plea for the development of effective approaches, which in most cases will require a long-term process through which viable national, regional and local systems can evolve. Foster (2006) comes to a similar conclusion and sees this approach to resource governance and information provision to be functioning at both the micro- and macro-level and calls the desired approach a 'top-down facilitation of local actions'.

A number of major issues will have to be addressed from the beginning to encourage stakeholders to be more willing to contribute to the management efforts, in particular (Burke and Moench, 2000):

- Valuation of groundwater: stakeholders respond to economic factors

- Scientific understanding and data: without understanding, people are often unwilling to act

- Education and social ethics: broad-based education is often central to building social support for management.

To become more systematic in developing flexible, integrated management systems, a strategic framework is seen as an essential precursor and progressive instrument for effective groundwater management (Burke and Moench, 2000; Global Water Partnership, 2002). In it, the intended relationships between diverse sets of interventions or management approaches and the development goals are specified. It should also specify the relationship between the diverse set of interventions themselves (individual, community and government roles and educational, economic, legal and regulatory mechanisms) - how together they are to form an approach to management that is internally consistent. A descriptive model change process for groundwater management is illustrated in Fig. 1 (Burke and Moench, 2000). 


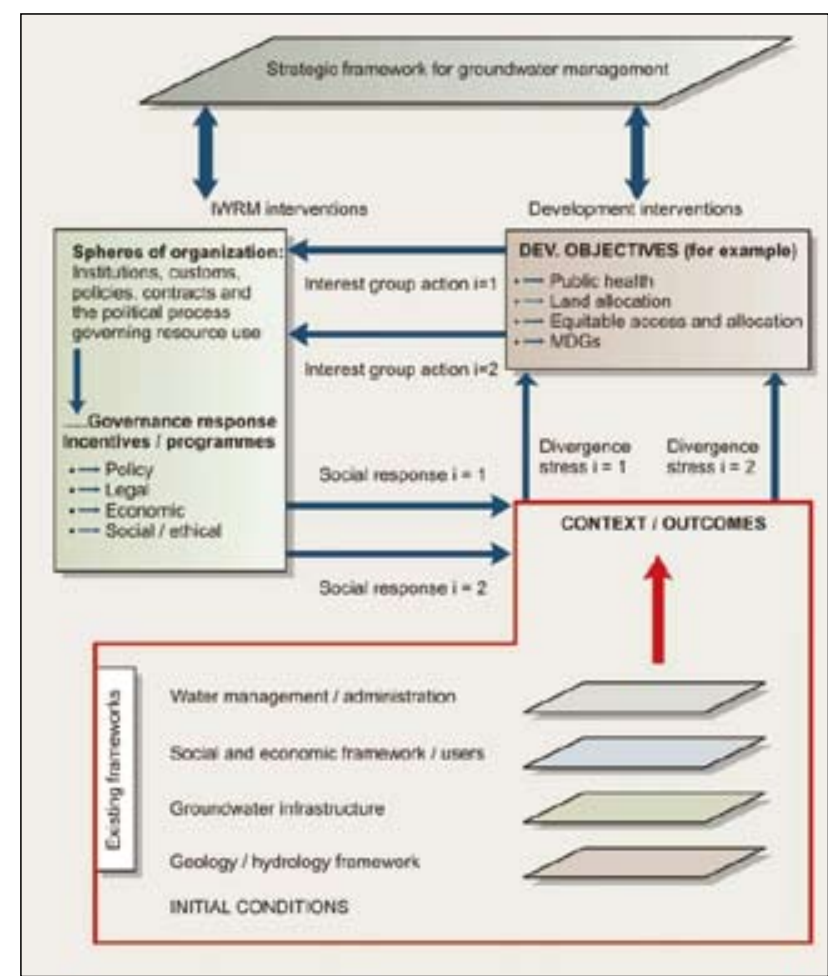

Figure 1

Descriptive model change process in groundwater management (Burke and Moench, 2000)

One must take note, that such a strategic, multi-stakeholderdriven approach also still remains the major challenge in Africa for IWRM implementation as a whole. To make progress in this regard, the SADC Multi-Stakeholder Water Dialogue was introduced a few years ago (Global Water Partnership, 2008). It is therefore crucial that groundwater becomes an integral part of already active, major country and regional development / water resource management initiatives. Examples are:

- The development of integrated water resource management and water efficiency plans in all countries

- The widely supported and implemented Rural Water Supply and Sanitation Initiative (RWSSI) in Africa, which, inter alia, promotes the utilisation of a wide range of appropriate technologies, including improved shallow wells and boreholes fitted with hand pumps, spring development and rain-water harvesting as well as the maintenance of infrastructure by local communities (African Development Bank Group, 2005)

- Devolution of water resource management to appropriate lower levels, which will allow widespread stakeholder participation, is being implemented in many parts of Africa. In SADC, water resource management, including the management of groundwater resources, is to take place in basin organisations and the provision of water services is to be the responsibility of local government (SADC, 2006).

A major opportunity has arisen to take continent-wide action through a resolution by the African Ministers Council on Water (AMCOW) taken in 2007 at its $6^{\text {th }}$ Ordinary Session in Brazzaville, namely that AMCOW would become the custodian of a continent-wide strategic groundwater initiative. Its vision is expressed in a roadmap for an African Groundwater Commission which is to function under the umbrella of AMCOW to facilitate and direct regional, national, and international action on a number of fronts (AMCOW, 2008):

\section{Vision}

An Africa where groundwater resources are valued and utilised sustainably by empowered stakeholders.

\section{Thrusts for action}

\section{Awareness}

This thrust must result in a widespread awareness of groundwater, its developmental role, its hydrological and ecosystem function, its vulnerability to human impact and approaches to its sustainable utilisation by key stakeholders at all levels.

\section{Capacity}

This thrust must result in appropriate capacity, including policy and legislation, and institutional and human resources, to plan and implement sustainable groundwater utilisation at all levels.

\section{Knowledge}

This thrust must result in a knowledge base, including monitoring networks, resource assessment, best practice database, information systems and fundamental sciences, to enable the optimal utilisation of groundwater within an integrated water resource management (IWRM) framework.

The first two practical groundwater resolutions taken by AMCOW (2008) must be seen as very strategic in their emphasis of the need to create synergies with major existing initiatives, namely:

- Promote the institutionalisation of groundwater management by river basin organisations to ensure regional ownership of the initiative

- Create synergy with the RWSSI to ensure groundwater's inclusion in resource assessment and the sustainable management of groundwater resources.

Very significantly, the SADC has already taken the lead with a process, together with AMCOW, towards a stakeholder-responsive broad-based programme and approach to capacity-building for the integration of groundwater resource management into the region's IWRM initiative. Starting with a workshop in 2008, this could be followed in 2009 with the $3^{\text {rd }}$ SADC Water Dialogue, this time focusing on groundwater (SADC, 2008). This would be a major step forward for groundwater in the region, given the direction of Burke and Moench (2000) that, unless dialogue occurs, the perspectives of key stakeholders are unlikely to be reflected.

What can be seen for this particular region of Africa is that processes are underway to try to address IWRM more comprehensively, with the intention of making groundwater an important part of the overall initiative.

\section{Conclusions}

The SADC region can be seen as representative of the wider African key development issue of poverty alleviation. Achieving water security is seen to be a crucial contribution to this regional goal. Given the highly spread-out nature of this target population, particularly in rural and informal urban areas, ubiquitous groundwater resources should be playing a strategic role in this region. However, despite the inability of bulk water supply 
solutions to address most of the widespread and diffuse water demand required to meet the remaining community water supply backlogs, there is still a general bias towards surface water resources in the region.

While the SADC is leading the other regional economic communities in Africa in terms of addressing IWRM, and groundwater as part of it, in its comprehensive regional water resource policies and strategies, the performance in sustainable utilisation and management of groundwater resources in individual SADC countries must still be generally rated as 'below expectation', according to a recent scoping study and compared to relevant international best practice.

A key finding has been that groundwater management links to groundwater-dependent sectors like agriculture, rural development, health and environment are not well established in policy or in practice. Internationally, there is a recognition that such a situation, although quite common, can only be addressed through a long-term process through which viable national, regional and local systems can evolve, within a strategic framework in which these intended relationships between diverse sets of interventions or management approaches and the development goals are brought out. Key issues are clarity on the roles and responsibilities of different institutions and the creation of effective co-ordination mechanisms between different agencies.

The IWRM and the water efficiency plans that each country is committed to develop, offer the ideal opportunity to mainstream groundwater resource management in this way. Such groundwater components of national plans could also be the forerunner for addressing groundwater in basin plans. The AMCOW resolution on the institutionalisation of groundwater opens the door to such action.

A number of major issues will have to be addressed from the beginning to make stakeholders more willing to contribute to the management efforts. Appropriate valuation of groundwater resources, with which very diverse stakeholders can identify, should be seen as an essential precursor to its sustainable management. Furthermore, without scientific understanding and data, people will remain unwilling to act. Last, but not least, broad-based education is often central to building social support for management.

It is clear that a lack of appropriate valuation of the role of groundwater in SADC must be seen as the main cause for its inadequate mainstreaming as part of IWRM and national development strategies and programmes. The fresh thinking generated through the shift in political priorities from water for basic needs to water for growth and development should also take groundwater into a more sustainable utilisation environment, requiring integrated management and assessment. The new strategic initiatives for groundwater at both a continental and sub-regional level by AMCOW and SADC respectively provide a major opportunity to take this forward in a multi-partnership approach.

\section{References}

AFRICAN DEVELOPMENT GROUP (2005) The Rural Water Supply and Sanitation Initiative. 22 April 2005, United Nations, New York. AMCOW (2008) Roadmap for the Africa Groundwater Commission. UNEP/UNESCO/UWC: Nairobi, Kenya.

BGR, CAP-NET, WATERNET, WA-NET (2007) Capacity Building for Groundwater Management in West and Southern Africa. Geozentrum: Hannover.

BRAUNE E, HOLLINGWORTH B, XU Y, NEL M, MAHED G and SOLOMON H (2008) Protocol for the Assessment of the Status of Sustainable Utilization and Management of Groundwater Resources
- With Special Reference to Southern Africa. WRC Report No. TT 318/08. Water Research Commission, Pretoria, South Africa.

BURKE JJ and MOENCH MH (2000) Groundwater and Society: Resources, Tensions and Opportunities. New York: United Nations, New York.

DWAF (2008) Department of Water Affairs and Forestry Seminar on Water for Growth and Development, 17.8.08. Stockholm Water Week 2008, Sweden.

ECONOMIC COMMISSION FOR AFRICA (2006) Southern Africa Water Development Report. ECA/SA/TPUB/2005/4.

ECONOMIC COMMISSION FOR AFRICA, ORGANISATION FOR AFRICAN UNITY AND AFRICAN DEVELOPMENT BANK (2000) Safeguarding Life and Development in Africa. A Vision for Water Resources Management in the $21^{\text {st }}$ Century. African Caucus Presentations - Second World Water Forum, The Hague, The Netherlands, 18 March 2000.

FOOD AND AGRICULTURAL ORGANIZATION OF THE UNITED NATIONS (2003) Groundwater Management - The Search for Practical Approaches. Water Reports 25. Rome: FAO.

FOSTER S (2006) Groundwater for Life and Livelihoods - The Framework for Sustainable Use. Presentation at 4th World Water Forum. 18 March 2006, Mexico. (www.iah.org).

GLOBAL WATER PARTNERSHIP (2000) Integrated Water Resources Management. GWP Catalyzing Change Series.

GLOBAL WATER PARTNERSHIP (2002) The Policy Guidance and Operational Tools on IWRM.

GWP (2008) The SADC Multi-Stakeholder Water Dialogue. Maseru, Lesotho 14-15 May 2008. GWP Information Note.

INTEGRATED REGIONAL INFORMATION NETWORKS (2002) Swaziland: Need for better management of water resources. www. reliefweb.int.

MOLAPO P, PANDEY SK and PUYOO S (2000) Groundwater Resource Management in the SADC Region: A Field of Regional Cooperation; IAH 2000 Conference, Cape Town.

MOLAPO P and PUYOO S (2002) Transboundary Aquifer Management in the Context of Integrated Water Resources Management in the Southern African Development Community (SADC) region. Proc. Int. Workshop. 2-4 June 2002, Tripoli, Libya.

SADC (2000) Revised Protocol on Shared Watercourses in the Southern African Development Community (SADC).

SADC, WSCU (2001) Situation Analysis Report. Report No.1.

SADC (2003) Regional Indicative Strategic Development Plan.

SADC (2005) Regional Strategic Action Plan for Integrated Water Resource Management.

SADC (2006) Regional Water Policy.

SADC (2008) Announcement for SADC/AMCOW Workshop on Groundwater for Development in the SADC IWRM Initiative. 18-19 November 2008, Gaborone, Botswana.

SUNGURO S, BEEKMAN HE and ERBEL K (2000) Groundwater Regulation and Guidelines: Crucial Components of Integrated Catchment Management in Zimbabwe. 'I' WARFSA/WaterNet Symposium: Sustainable Use of Water Resources. 1-2 November 2000, Maputo, Mozambique.

UNESCO (1999) Integrated Drought Management-Lessons for subSaharan Africa. Proceedings of the International Conference. UNESCO-IHP, Pretoria, September 1999.

UNITED NATIONS (1992) Agenda 21, Chapter 18. United Nations Conference on Environment and Development. 3-14 June 1992, Rio de Janeiro, Brazil..

UN MILLENNIUM PROJECT TASK FORCE ON WATER AND SANITATION (2005) Health, Dignity and Development: What Will It Take? Millennium Project. Stockholm International Water Institute, Stockholm, Sweden.

WELLFIELD CONSULTING SERVICES \& BRITISH GEOLOGICAL SURVEY (2003) SADC: Regional Situation Analysis. Report No. RFP \# WB 1861-571/02.

WORLD WATER COUNCIL (2006) Water Resources Development in Africa. Africa Regional Document. $4^{\text {th }}$ World Water Forum, 16-22 March 2006, Mexico City, Mexico.

WSSD PLAN OF IMPLEMENTATION (2002) World Summit on Sustainable Development, Johannesburg 2002 (www.johannesburgsummit.org). 
XU and BEEKMAN (eds.) (2003) Groundwater Recharge Estimation in Southern Africa, UNESCO IHP Series No. 64, published by UNESCO Paris. ISNB 92-9220-000-3.

XU Y and USHER B (eds.) (2006) Groundwater Pollution in Africa.
Published by Taylor \& Francis / Balkema, ISBN 10: 0-415-41167-X. UK.

ZAMBIAN WATER PARTNERSHIP (2008) Integrated Water Resources Management (IWRM) Plan for Zambia. 